\title{
Functionally Graded Stainless Steel Fabricated by Direct Laser Deposition: Anisotropy of Mechanical Properties and Hardness
}

\author{
Qiang Wang ${ }^{1,2,3} \cdot$ Song Zhang ${ }^{2} \cdot$ Chun-Hua Zhang ${ }^{2} \cdot$ Chen-Liang $\mathrm{Wu}^{2} \cdot$ Ling Ren $^{4} \cdot$ Jian-Qiang Wang $^{4} \cdot$ \\ Jiang Chen ${ }^{3}$
}

Received: 11 June 2017/Revised: 31 July 2017/Published online: 27 October 2017

(C) The Chinese Society for Metals and Springer-Verlag GmbH Germany 2017

\begin{abstract}
Direct laser metal deposition is a kind of advanced rapid manufacturing technology, which can produce near net shape parts by depositing metal powders layer by layer. This study demonstrates fabrication, the anisotropy of mechanical properties and hardness of a graded steel. The characteristics of constituent phases, microstructure, mechanical anisotropy, and microhardness were investigated using electron backscatter diffraction, optical microscopy, tensile test machine, and microhardness tester. It was found that the graded steel is dense and free of cracks. The crystal structures of the as-built samples evolved in three grades from fcc structures to fcc + bcc structures and then to bcc + fcc structures. Samples in $x$ and $z$ directions showed obvious mechanical anisotropy. The samples machined in $x$ direction showed higher strength and lower elongation than those machined in $z$ direction due to the presence of lack-of-fusion pores and the higher metallurgical bonding between layers in the $x$ direction. The microhardness of the as-built samples increased along the cross section from the substrate $(159.7 \mathrm{HV})$ to the top surface $(545.4 \mathrm{HV})$.
\end{abstract}

KEY WORDS: Graded steel; Direct laser metal deposition; Electron backscatter diffraction (EBSD); Anisotropy of mechanical properties

\section{Introduction}

Steel alloys have been extensively used in different fields, such as aerospace, energy science, nuclear, load-bearing orthopedic, and dental devices. The developments in

Available online at http://link.springer.com/journal/40195.

Qiang Wang

mfqwang@163.com

1 School of Stomatology, China Medical University, Shenyang 110002, China

2 School of Materials Science and Engineering, Shenyang University of Technology, Shenyang 110870, China

3 Shenyang Dalu Laser Group Co., Ltd., Shenyang 110002, China

4 Institute of Metal Research, Chinese Academy of Sciences, Shenyang 110016, China additive manufacturing (AM) techniques such as selective laser melting (SLM) and direct laser metal deposition (DLMD) have enabled fabrication of steel alloys with precisely controlled micro-architectures [1-3]. AM is a kind of advanced rapid manufacturing technology, which can produce near net shape parts by depositing metal powders layer by layer. The building height of the structure is controlled by movement in $z$ direction of the laser and powder delivery system [4]. Additive manufacturing can fabricate a large variety of metals including those with high melting points such as titanium alloys [5-8], steels [9-14], nickel base super-alloys [15-18], and cobalt base alloys $[19,20]$. Additive manufacturing also offers a unique way of graded microstructure control with a high degree of design freedom [21, 22]. Functionally graded materials (FGMs), which possess gradients in properties such as hardness or density, are a potential solution to the requirements in extreme environments, which requires 
Table 1 Chemical composition of steel powders used in DLMD (wt $\%$ )

\begin{tabular}{lllllllll}
\hline & C & Si & B & Cr & Ni & Mo & Mn & Fe \\
\hline Alloy powder 1 & $\leq 0.07$ & 0.61 & 0.4 & 17.89 & 13.1 & 2.49 & $\leq 0.49$ & Bal. \\
Alloy powder 2 & $\leq 0.07$ & 0.83 & 0.4 & 17.33 & 8.54 & 1.89 & $\leq 0.49$ & Bal. \\
Alloy powder 3 & $\leq 0.14$ & 1.04 & 1 & 16.78 & 3.98 & 1.30 & $\leq 0.50$ & Bal. \\
\hline
\end{tabular}

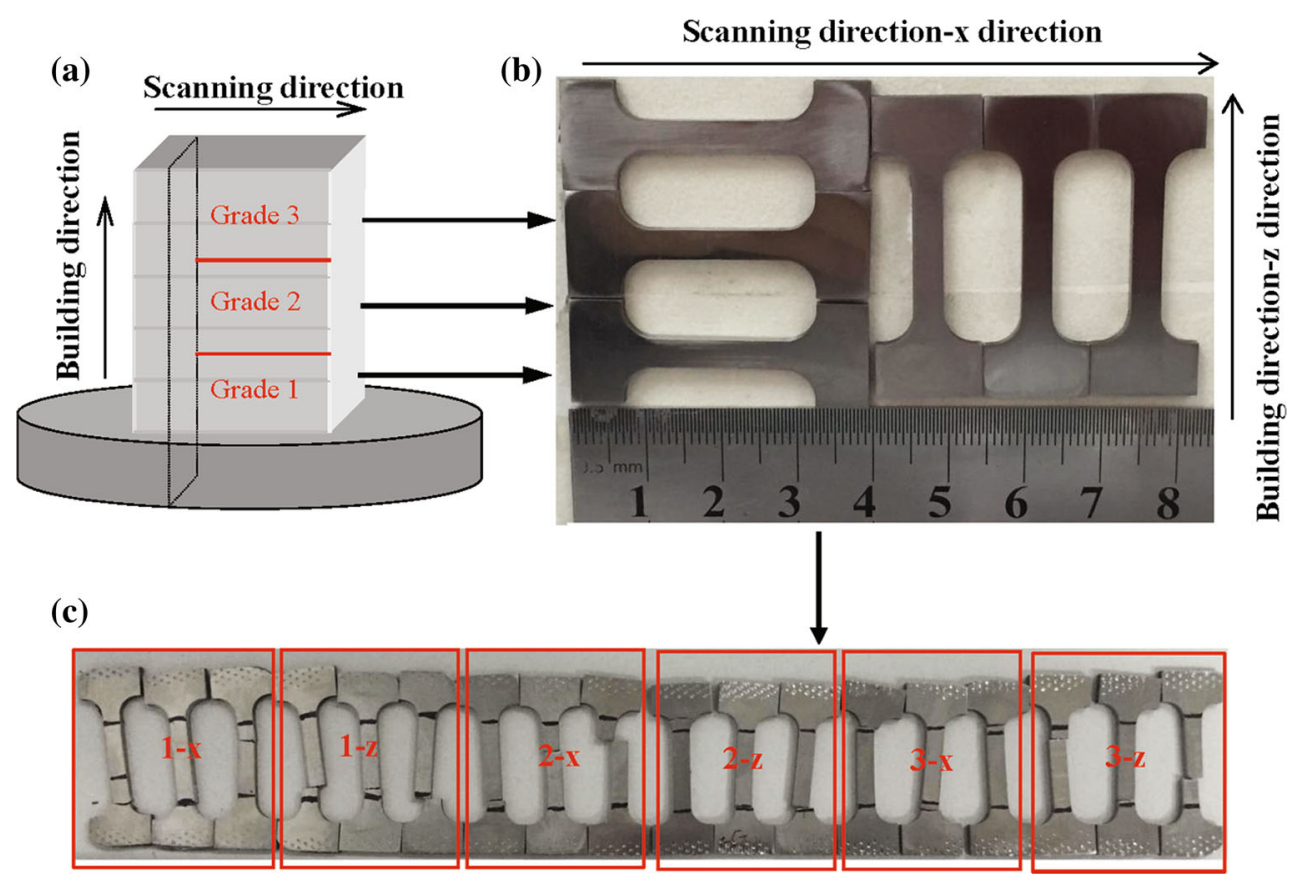

Fig. 1 Schematic of the DLMD process a, mechanical test samples before $\mathbf{b}$ and after $\mathbf{c}$ fracture
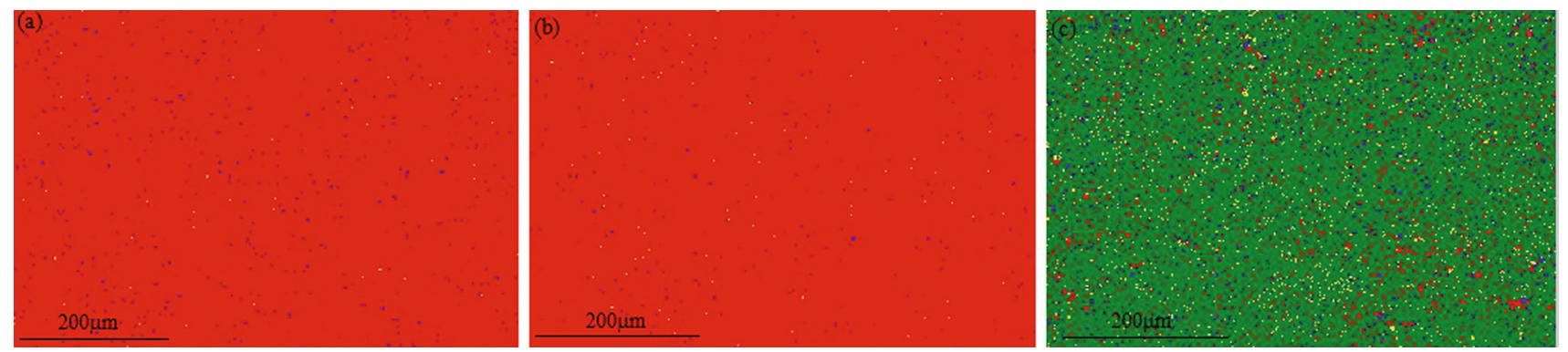

Fig. 2 Phase distributions of the as-built samples by EBSD: a the first grade, $\mathbf{b}$ the second grade, $\mathbf{c}$ the third grade. Red: fcc; green: bcc; yellow: $\mathrm{C}_{6} \mathrm{Cr}_{23}$; blue: $\mathrm{C}_{3} \mathrm{Fe}_{7}$

components with properties that vary with location in the part [22]. Attention has been paid to the principle for obtaining graded structure mainly in the metal-based functionally graded materials [23]. Therefore, AM can be used to create FGMs by changing the relative fractions of two or more powders fed into the melt pool as a function of position [24, 25].
The microstructural characteristics (e.g., morphology and grain size) of AM parts are strongly sensitive to their thermal history during the build, which may include high heating/cooling rates, significant temperature gradients, bulk temperature rises and more [26]. Due to laser attenuation and radiation effects, lower incident energy can tend to result in finer equiaxed structures while higher incident energy generally results in columnar grains and coarser 


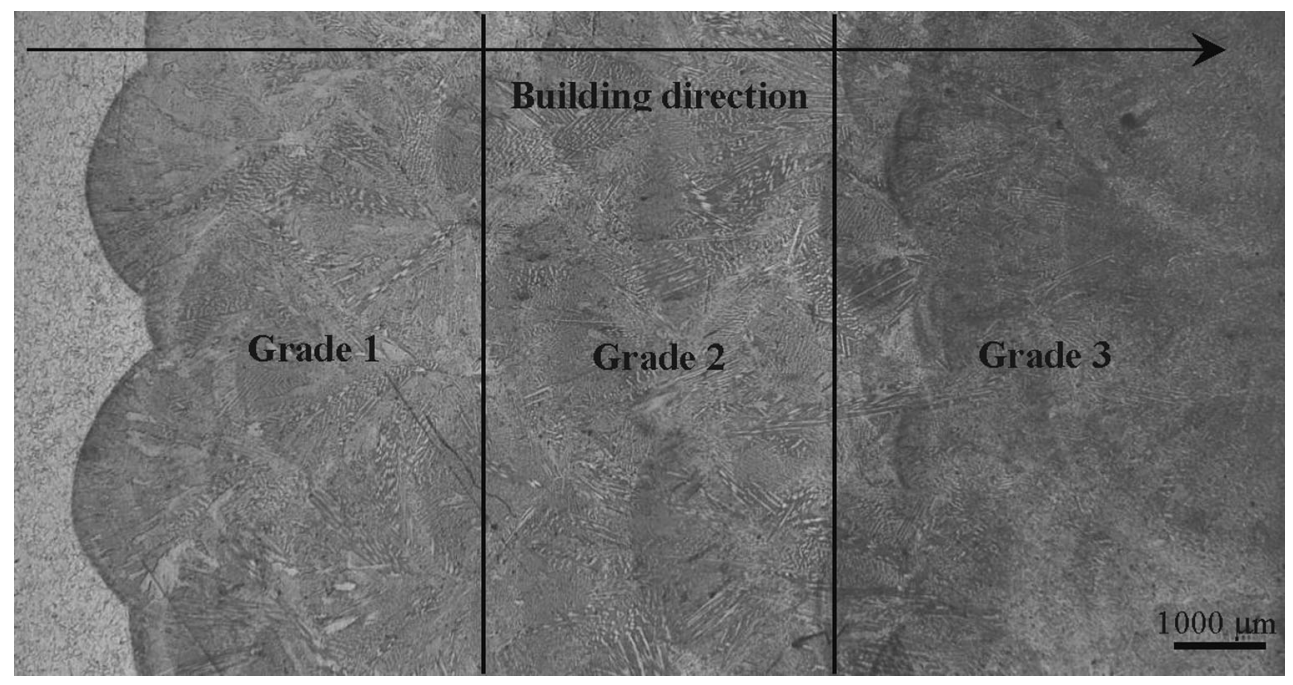

Fig. 3 Macroscopic morphologies of the graded steel by DLMD

microstructures [25-27]. A defect-free, homogenous microstructure can be obtained under a narrow range of parameters [28-30]. It was found that many possible combinations of laser traverse velocity and powder feed rate will result in negligible porosity provided that the ratio of powder feed rate to laser traverse velocity does not exceed a maximum level [31]. The control of shape and performance for the precision large-scale metal parts with stainless steel 316L by DLMD was reported by Ma et al. [32]. The thickness of deposition layer in a single layer and the multi-layers is different. The previously deposited layers are reheated when a new layer is deposited on top of them. There are certain parameters which can affect the properties and precision of the as-built samples by DLMD. DLMD process is more complicated than a series of successive solidifications of molten pools [28].

It is also known that many alloys fabricated by AM (DLMD and SLM) are highly anisotropic materials, which mean that they have different properties in different crystallographic directions [33-37]. Much literature has reported the production processes and basic material properties. However, there has been limited knowledge about the mechanical anisotropy of the metal materials by AM. The main aim of this study is to further investigate the mechanical anisotropy of a graded stainless steel by DLMD and provides experimental data to appraise the application of existing design methods to sections produced through this novel manufacturing process.

\section{Experimental}

Alloy powders with a particle size ranged from 53 to $190 \mu \mathrm{m}$ are used in DLMD processes. The chemical composition of the steel powders used in the present study is shown in Table 1. Three different alloy compositions were deposited in different grades in one bulk sample by DLMD. Gradient compositions were designed according to Schaeffler equivalent formulas which was reported in our previous studies [25, 38]. By adjusting the $\mathrm{Cr} / \mathrm{Ni}$ ratio of alloy powders, the chemical composition of alloy powders was determined. Alloy powder 1, alloy powder 2, and alloy powder 3 are deposited in grade 1 , grade 2 , and grade 3 , respectively. The used substrate $(\varnothing 90 \mathrm{~mm}$, thickness $20 \mathrm{~mm}$ ) is a kind of stainless steel. Ytterbium laser system (LMD-3000) was used in DLMD processing of graded steel to produce a laser beam with a wavelength of $1070 \mathrm{~nm}$. Electron backscatter diffraction (EBSD) was used to investigate the phase constitute of the samples. The detail of fabrication process and EBSD examination can be found in our previous study [25].

The as-built samples were cut from the substrate plate. Building and scanning directions are illustrated in Fig. 1. The specimens for tensile test as shown in Fig. 1 in different grades were prepared by wire electrical discharge machine, for both of the building direction ( $z$ direction) and scanning direction ( $x$ direction, perpendicular to the building direction). Before starting the test, all the specimens were ground by $\mathrm{SiC}$ paper to remove the surface ripples and flash. The tensile test was performed at room temperature on a universal testing machine (MTS, 5582, USA), with a tensile rate of $1 \mathrm{~mm} / \mathrm{min}$. An average value of three specimens was taken for each material. The tensile properties, including ultimate tensile strength $\left(\sigma_{\mathrm{b}}\right)$, yield strength $\left(\sigma_{0.2}\right)$, elongation and reduction of area $(\psi)$, were obtained. The samples after tensile test are shown in Fig. 1c.

The Vickers hardness along the cross section was measured with a $200 \mathrm{~g}$ load for $10 \mathrm{~s}$ by a Vickers hardness tester (Leco, LM 247AT). A minimum of three 

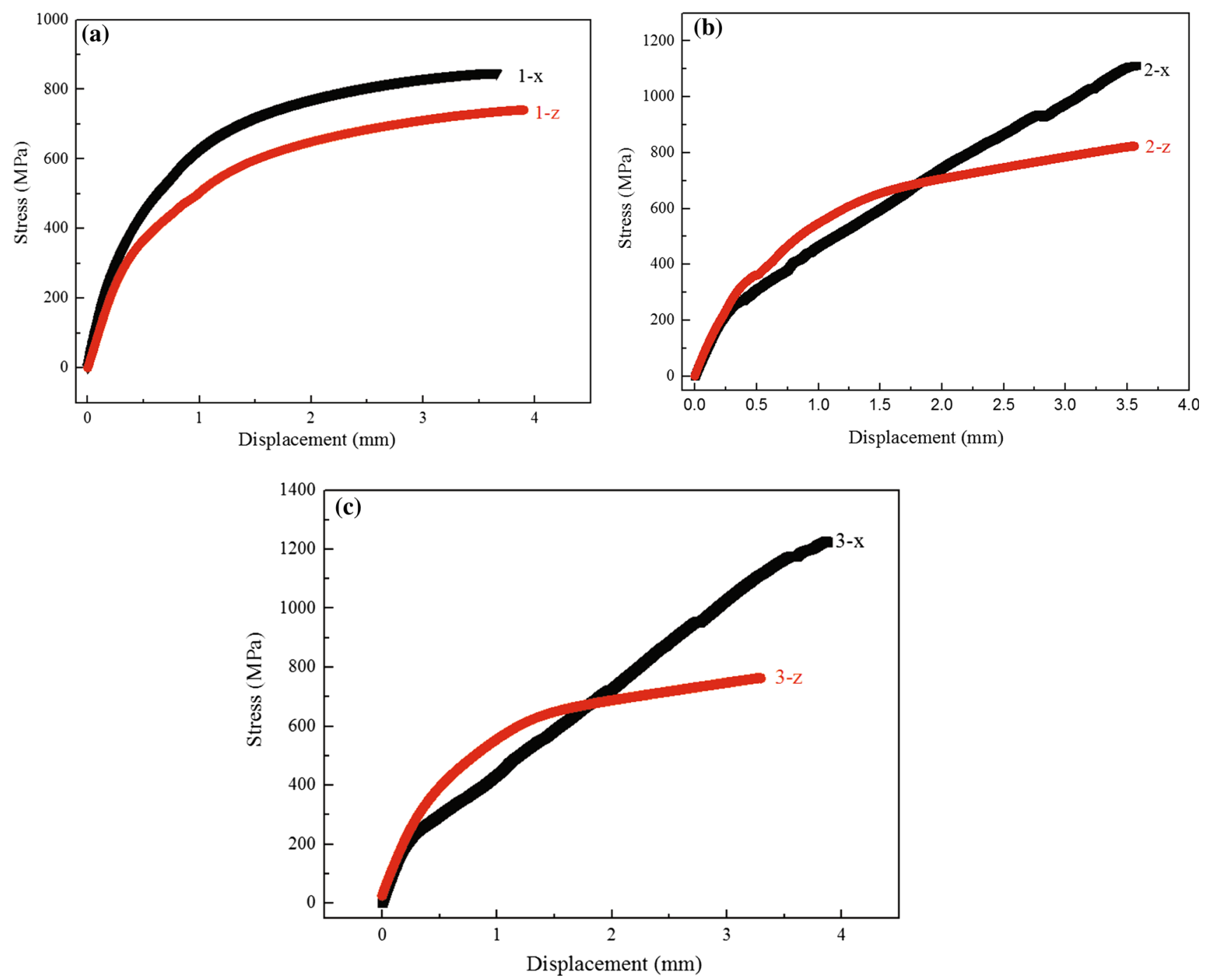

Fig. 4 Typical tensile stress-strain curves a the samples in the first grade; $\mathbf{b}$ the samples in the second grade; $\mathbf{c}$ the samples in the third grade

measurements were performed for each position to determine the average microhardness value.

\section{Results and Discussion}

\subsection{Phase Constitute and Macrostructure}

The distributions of fcc and bcc phases in different grades for the as-built samples were demonstrated in Fig. 2. The first and second grades mainly contain fcc phase while the third grade mainly contains bcc phase with the amount of about $8.16-9.15 \%$ fcc phase. The phase evolution caused in this process is the austenite which is first changed into the mixture of austenite and ferrite, and then transformed to mainly ferrite. Austenite phase with a trace of $\mathrm{C}_{6} \mathrm{Cr}_{23}$ and $\mathrm{C}_{3} \mathrm{Fe}_{7}$ phases is detected in the third grade for all the asbuilt samples. The reason for this process is that the reduction of $\mathrm{Ni}$ element content of alloy cuts down the austenite stable region during the continuous cooling transition [37, 39].

Figure 3 shows the macroscopic morphology of the graded steel by DLMD. The as-built graded steel was free of macroholes, cracks or any other defects. The absence of little holes and cracks demonstrates that the processing parameters optimized in the present work ensure a high quality of the built samples.

\subsection{Mechanical Properties}

The typical tensile stress-strain curves of the alloys in different grades are shown in Fig. 4. Here, 1- $x, 2-x$, and $3-x$ represent the alloys in grade 1 , grade 2 , and grade 3 . " $x$ " means the scanning direction which is perpendicular to the building direction; $1-y, 2-y$, and 3-y represent the alloys in grade 1 , grade 2 , and grade 3 . " $y$ " means the building 
Table 2 Mechanical properties of the samples

\begin{tabular}{|c|c|c|c|c|}
\hline Materials & $\begin{array}{l}\text { Yield strength, } \\
\sigma_{0.2}(\mathrm{MPa})\end{array}$ & $\begin{array}{l}\text { Tensile strength, } \\
\sigma_{\mathrm{b}}(\mathrm{MPa})\end{array}$ & Elongation $(\%)$ & $\begin{array}{l}\text { Reduction of } \\
\text { area, } \psi(\%)\end{array}$ \\
\hline First grade- $x$ & $529 \pm 30$ & $951 \pm 79$ & $6.8 \pm 1.5$ & $8.4 \pm 3.9$ \\
\hline First grade- $z$ & $501 \pm 19$ & $765 \pm 20$ & $12.0 \pm 0.17$ & $10 \pm 1.7$ \\
\hline Second grade- $x$ & $485 \pm 40$ & $1050 \pm 91$ & $0.67 \pm 0.39$ & $1.9 \pm 1.4$ \\
\hline Second grade $-z$ & $469 \pm 38$ & $761 \pm 49$ & $10 \pm 0.57$ & $8.1 \pm 1.0$ \\
\hline Third grade $-x$ & $675 \pm 114$ & $1056 \pm 207$ & $0.87 \pm 0.55$ & $1.1 \pm 0.99$ \\
\hline Third grade- $z$ & $507 \pm 23$ & $721 \pm 30$ & $12 \pm 0.77$ & $8.9 \pm 0.42$ \\
\hline LENS SS16L [33] ( $x$ direction) & 576 & 776 & 33 & - \\
\hline LENS SS16L [33] ( $z$ direction) & 479 & 703 & 46 & - \\
\hline LMDS part [35] ( $z$ direction $)$ & 558 & 639 & 21 & - \\
\hline LMDS part [35] ( $x$ direction) & 352 & 536 & 46 & - \\
\hline DLD/Single-Built 316L(as-built) [39] & $405-415$ & $620-660$ & $32-40$ & - \\
\hline DLD/Single-Built 316L(heat-treated) [39] & $325-355$ & $600-620$ & $42-43$ & - \\
\hline DLD/Nine-Built (as-built) [39] & $465-485$ & $660-685$ & $12-20$ & - \\
\hline
\end{tabular}

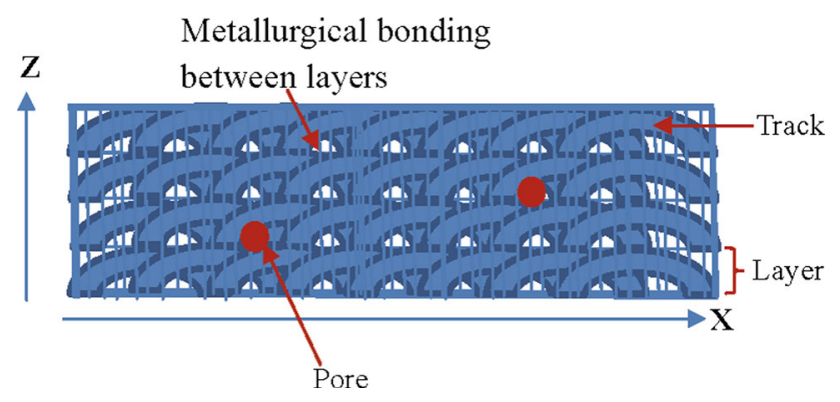

Fig. 5 Schematic diagram of the mechanical anisotropy

direction. The illustration about directions can also be found in Fig. 1. The yield strength, the ultimate tensile strength, the total elongation and reduction of area to rupture are listed in Table 2 with the data obtained by other literature for reference. The mechanical values achieved in the present study are comparable with the results from other literature and the alloys fabricated from the traditional processing [40]. In the first grade, the yield strength $\left(\sigma_{0.2}\right)$ and the tensile strength $\left(\sigma_{\mathrm{b}}\right)$ of the alloy in $x$ direction were about 529 and $951 \mathrm{MPa}$, while the elongation and reduction of area were about 6.8 and $8.4 \%$, respectively. However, $\sigma_{0.2}, \sigma_{\mathrm{b}}$, the elongation and reduction of the area of $1-y$ are 501, $765 \mathrm{MPa}, 12$ and $10 \%$, respectively. It indicates that $\sigma_{0.2}$ and $\sigma_{\mathrm{b}}$ in $x$ direction are about 5.4 and $20 \%$ higher than these in $z$ direction, respectively. The ductility in $z$ direction is better than that in $x$ direction. In the second grade, $\sigma_{0.2}, \sigma_{\mathrm{b}}$, the elongation and reduction of the area in $x$ direction are $485,1050 \mathrm{MPa}, 0.67$ and $1.9 \%$, respectively. However, $\sigma_{0.2}, \sigma_{\mathrm{b}}$, the elongation and reduction of area in $z$ direction are $469,761 \mathrm{MPa}, 10$ and $8.1 \%$, respectively. The similar phenomenon was observed in the third grade. The tensile strength $\left(\sigma_{\mathrm{b}}\right)$ increased gradually from the first grade to the third grade in $x$ direction. However, $\sigma_{\mathrm{b}}$ was not increased in $z$ direction. The phenomenon can be explained in the following parts as shown in Fig. 5. Mechanical anisotropy in different grades is characterized. The values of $\sigma_{0.2}$ and $\sigma_{\mathrm{b}}$ measured in $x$ direction were higher than those in $z$ direction. An inverse relationship for elongation and reduction of the area was observed. The reason for the mechanical anisotropy can be explained by two factors as shown in Fig. 5. For the alloys that were built in $z$ direction, the weak metallurgical bonding between layers accounted for the relatively lower values in tensile properties and higher ductility [35]. As shown in Fig. 5, the metallurgical bonding in $x$ direction is track-track bonding like fried dough twists. The metallurgical bonding in $z$ direction is layer-layer bonding like plane bonding. Another factor is that the pores in the DLMD samples which is known as lack-of-fusion pores and is extremely harmful to mechanical properties [31]. The loading direction is normal to the orientation of pores. Therefore, the pores tend to be torn apart from the samples in $z$ direction. The loading is nearly parallel to the flat pores imposing compression stress upon the pores locally, which helps seal and close the pores for the samples in $x$ direction [41]. Fracture morphologies of the tensile samples are shown in Fig. 6. As for the $1-x$ and $1-z$ samples, it is observed that the primary fracture mechanism is ductile mode, and the mean size of the dimples is similar to that of cellular grains. The undesirable closed pores on a scale of 10-20 $\mu \mathrm{m}$ are observed on the fracture surfaces (Fig. 6a-d) which were explained in the schematic diagram of Fig. 5. 

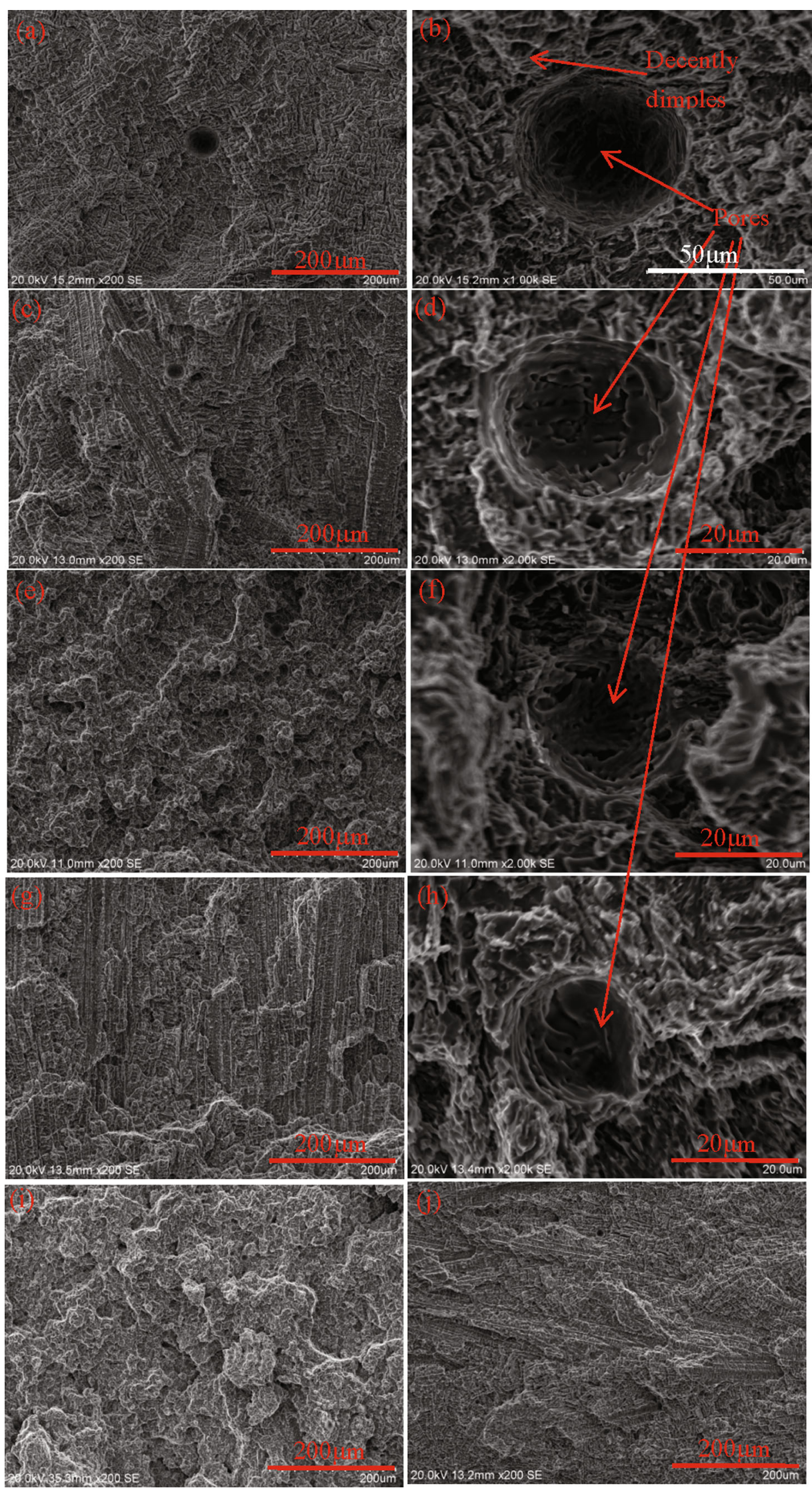
4Fig. 6 SEM micrographs of the fracture surfaces of the samples: $\mathbf{a}$ and $\mathbf{b}$ the samples in $x$ direction in the first grade; $\mathbf{c}$ and $\mathbf{d}$ the samples in the $z$ direction in the first grade; $\mathbf{e}$ and $\mathbf{f}$ the samples in $x$ direction in the second grade; $\mathbf{g}$ and $\mathbf{h}$ the samples in $z$ direction in the second grade; $\mathbf{i}$ the samples in $x$ direction in the third grade; $\mathbf{j}$ the samples in $z$ direction in the third grade

These pores show smooth surfaces decorated with unmelted or partially melted powder particles suggesting that this layer was not completely remelted during the subsequent building, which was also reported by other researchers $[34,41,42]$. It was believed that these pores act as the main sites triggering fracture. However, the fracture morphologies of the 2- $x$ (Fig. 6e, f) and 2-z (Fig. 6g, h) samples are different. As for the $2-z$ samples, many quasi-cleavage facet stages are observed. Further, the small dimples in the dendritic structures are different to the 2- $x$ samples. The fracture modes of the specimen are different at different directions. The similar difference of the fracture morphologies for the $3-x$ and $3-z$ samples is also observed (Fig. 6i, j). When combine Fig. 4 with Fig. 6, it can be seen that the samples of the first grade show a typical ductile fracture in $x$ and $y$ directions. However, the samples of the second and third grades in $x$ direction show a brittle rupture while those in $z$ direction show typical ductile fracture.

\subsection{Microhardness}

The hardness of the as-built samples from the heat affected substrate to the top surface is shown in Fig. 1. The microhardness of the heat affected zone in the substrate is in the range of $159.7 \mathrm{HV}$. In grade 1 , the average microhardness is $254.2 \mathrm{HV}$. The average microhardness increases to $279.5 \mathrm{HV}$ in grade 2 . In grade 3 , the average microhardness increases to the highest value $537.4 \mathrm{HV}$. The result indicates that the microhardness increases along the cross section with the composition change in different grades. The third grade mainly consists of $\alpha$ phase (bcc, ferrite) contributing to a higher hardness value than those of the first two grades. It can also be observed that the microhardness of the same as-built samples gradually increased with increasing the distance from the substrate. The phenomenon occurred due to the microstructure evolution from coarser-structured fcc to bcc. The reduction of $\mathrm{Ni}$ increased the microhardness along the cross section of the samples due to the ductile fcc decrease and hard bcc increase, because the inherent characteristic of $\gamma$ is soft and $\alpha$ is hard. It was also reported that the relationship between the hardness and the average grain size of metal material can be described as follows [43, 44]:

$H_{\mathrm{s}}=H_{\mathrm{i}}+K d^{-1 / 2}$, where $H_{\mathrm{s}}$ is the hardness of the metal material, $H_{\mathrm{i}}$ and $K$ are the appropriate constants associated with the hardness measurements. Hardness increases with decreasing the average grain size. The average grain size $(d)$ decreases along the building direction from grade 1 to grade 3 , reflecting the evolution of hardness.

\section{Conclusions}

In the present study, graded steels are fabricated by DLMD. The anisotropies of mechanical properties and microhardness have been studied. The main conclusions can be drawn as follows:

1. The crystal structures of the as-built graded steel evolved from fcc structure to single fcc microstructure in grade 1 to fcc (mainly) + bcc structures in grade 2 and then to fcc + bcc (mainly) structures.

2. The as-fabricated samples show high tensile strengths but low elongation in $x$ direction while the results in $z$ direction are inverse. The mechanical anisotropies in different grades are characterized. Metallurgical bonding and pores contribute to the difference. It is important to eliminate or utilize mechanical anisotropy as for the DLMD samples.

3. The microhardness of the as-built samples increased along the cross section from the substrate $(159.7 \mathrm{HV})$ to the top surface (545.4 HV). The highest microhardness which can reach 545.4 HV was detected in the third grade. The increase in microhardness can be explained as the phase transition of fcc structure to two-phase fcc + bcc (mainly) structures. Furthermore, grain refinement contributes to the increase of microhardness.

Acknowledgements This work was financially supported by the National Key Research and Development Program of China (Grant Nos. 2016YFB1100204 and 2013ZX06002-002) and the Shenyang Science and Technology Funded Project (Grant Nos. 17-29-2-00, Y17-1-031 and Z17-2-002). Financial support by the Youth Foundation of School of Stomatology, China Medical University (Grant No. K101593-17-05) is gratefully acknowledged.

\section{References}

[1] L. Hao, S. Dadbakhsh, O. Seaman, M. Felstead, J. Mater. Process. Technol. 209, 5793 (2009)

[2] Q. Wang, L. Ren, X.P. Li, S.Y. Zhang, T.B. Sercombe, K. Yang, Mater. Sci. Eng. C 68, 519 (2016)

[3] C.M. Lin, Vacuum 121, 96 (2015)

[4] R.S. Amano, P.K. Rohatgi, Mater. Sci. Eng. A 528, 6680 (2011)

[5] P.C. Collins, R. Banerjee, S. Banerjee, H.L. Fraser, Mater. Sci. Eng. A 352, 118 (2003)

[6] B.C. Zhang, H.L. Liao, C. Coddet, Vacuum 95, 25 (2013) 
[7] G.Q. Wu, C.L. Shi, W. Sha, A.X. Sha, H.R. Jiang, Mater. Sci. Eng. A 575, 111 (2013)

[8] L. Bian, S.M. Thompson, N. Shamsaei, JOM 67, 629 (2015)

[9] R. Casati, J. Lemke, M. Vedani, J. Mater. Sci. Technol. 32, 738 (2016)

[10] C.H. Zhang, H. Zhang, C.L. Wu, S. Zhang, Z.L. Sun, S.Y. Dong, Vacuum 141, 181 (2017)

[11] Y. Xue, A. Pascu, M.F. Horstemeyer, L. Wang, P.T. Wang, Acta Mater. 58, 4029 (2010)

[12] J.K. Mickovski, I.J. Lazarev, J. Lazarev, J. Technol. Plast. 35, 61 (2010)

[13] D. Wu, X. Liang, Q. Li, L. Jiang, Int. J. Opt. 2010, 1 (2010)

[14] P. Ganesh, R. Kaul, G. Sasikala, H. Kumar, S. Venugopal, P. Tiwari, S. Rai, R.C. Prasad, L.M. Kukreja, Metallogr. Microstruct. Anal. 3, 36 (2014)

[15] P.L. Blackwell, J. Mater. Process. Technol. 170, 240 (2005)

[16] C.P. Paul, P. Ganesh, S.K. Mishra, P. Bhargava, J.A. Negi, K. Nath, Opt. Laser Technol. 39, 800 (2007)

[17] G.P. Dinda, K. Dasgupta, J. Mazumder, Mater. Sci. Eng. A 509, 98 (2009)

[18] P. Ganesh, R. Kaul, C.P. Paul, P. Tiwari, S.K. Rai, R.C. Prasad, L.M. Kukreja, Mater. Sci. Eng. A 527, 7490 (2010)

[19] G.D. Janaki Ram, B.E. Stucker, J. Manuf. Sci. Eng. 130, 024503 (2008)

[20] G.D. Janaki Ram, C.K. Esplin, B.E. Stucker, J. Mater. Sci. Mater. Med. 19, 2105 (2008)

[21] V.A. Popovich, E.V. Borisov, A.A. Popovich, VSh Sufiiarov, D.V. Masaylo, L. Alzina, Mater. Des. 114, 441 (2017)

[22] B.E. Carroll, R.A. Otis, J.P. Borgonia, J.O. Suh, R.P. Dillon, A.A. Shapiro, D.C. Hofmann, Z.K. Liu, A.M. Beese, Acta Mater. 108, 46 (2016)

[23] J.J. Sobczak, L. Drenchev, J. Mater. Sci. Technol. 29(4), 297 (2013)

[24] L.D. Bobbio, R.A. Otis, J.P. Borgonia, R.P. Dillon, A.A. Shapiro, Z.K. Liu, A.M. Beese, Acta Mater. 127, 133 (2017)

[25] Q. Wang, S. Zhang, C.H. Zhang, C.L. Wu, J.Q. Wang, J. Chen, Z.L. Sun, Vacuum 141, 68 (2017)
[26] N. Shamsaei, A. Yadollahia, L.K. Bian, S.M. Thompson, Addit. Manuf. 8, 12 (2015)

[27] C. Selcuk, Powder Metall. 54, 94-99 (2011)

[28] T. Amine, J.W. Newkirk, F. Liou, Case Stud. Therm. Eng. 3, 21-34 (2014)

[29] M. Jyotsna Dutta, L. Lin, Metall. Mater. Trans. A 40, 3001 (2009)

[30] B. Didier, S. Simon, Phys. Proc. 39, 455 (2012)

[31] J.B. Ferguson, B.F. Schultz, A.D. Moghadam, P.K. Rohatgi, J. Mater. Process. Technol. 19, 163 (2015)

[32] M.M. Ma, Z.M. Wang, D.Z. Wang, X.Y. Zeng, Opt. Laser Technol. 45, 209 (2013)

[33] A.A. Deev, P.A. Kuznetcov, S.N. Petrov, Phys. Proc. 83, 789 (2016)

[34] M. Ziętala, T. Durejko, M. Polański, I. Kunce, T. Płociński, W. Zieliński, M. Łazińska, W. Stępniowski, T. Czujko, K.J. Kurzydłowski, Z. Bojar, Mater. Sci. Eng. A 677, 1 (2016)

[35] P. Guo, B. Zou, C.Z. Huang, J. Mater. Proc. Technol. 240, 12 (2017)

[36] C. Buchanan, V.P. Matilainen, A. Salminen, L. Gardner, J. Constr. Steel Res. 136, 35 (2017)

[37] K. Zhang, S.J. Wang, W.J. Liu, X.F. Shang, Mater. Des. 55, 104 (2014)

[38] C.H. Zhang, H. Zhang, C.L. Wu, S. Zhang, Z.L. Sun, S.Y. Dong, Vacuum 141, 181 (2017)

[39] W. Guo, Dissertation for the doctoral degree, University of Central Florida, 2000

[40] F.Y. Dong, P. Zhang, J.C. Pang, Q.Q. Duan, Y.B. Ren, K. Yang, Z.F. Zhang, Acta Metall. Sin. (Engl. Lett.) 29, 140 (2016)

[41] C.L. Qiu, G.A. Ravi, C. Dance, A. Ranson, S. Dilworth, M.M. Attallah, J. Alloys Compd. 629, 351 (2015)

[42] A. Yadollahi, N. Shamsaei, S.M. Thompson, D.W. Seely, Mater. Sci. Eng. A 644, 171 (2015)

[43] S. Li, Q.W. Hu, X.Y. Zeng, S.Q. Ji, Appl. Surf. Sci. 240, 63 (2005)

[44] Y.S. Sato, M. Urata, H. Kokawa, K. Ikeda, Mater. Sci. Eng. A 354, 298 (2003) 